\title{
GUATEMALA: REPENSANDO EL VÍNCULO ENTRE JUVENTUD Y VIOLENCIA EN LA POSGUERRA
}

\author{
Guatemala: Rethinking the Link between Youth and Violence in the Postwar Period
}

\author{
Leslie Lemus
}

Resumen: Irónicamente, el tema de la violencia criminal es relevante en los países de Centroamérica tras el final de brutales episodios de violencia politica. Desde distintos enfoques, la atención al problema se ha centrado en cierto tipo de individuos como protagonistas del fenómeno: hombres jóvenes de áreas urbanas y sectores populares. Aunque estas perspectivas se basan en la evidencia disponible, es necesario examinar críticamente sus premisas e implicaciones. En este artículo se exponen reflexiones derivadas de diversas experiencias de investigación sobre el tema, y se propone una serie de aportes para repensar el vínculo entre juventud y violencia en Guatemala.

Palabras clave: juventud, jóvenes, violencia, zonas urbanas, políticas públicas.

Abstract: Currently, criminal violence is a relevant issue in most Central American countries, even after the end of brutal episodes of political violence. Different approaches have focused attention on a certain type of protagonist of the problem: young men from urban areas and popular sectors. Although these perspectives are based on available evidence, it is worthwhile to review their premises and implications. This article outlines the author's reflections derived from diverse research into the subject and proposes a series of ideas to revisit the link between youth and violence in Guatemala.

Keywords: youth, young people, violence, urban areas, public policy.

Leslie Lemus. Candidata a doctora en Ciencia Social con especialidad en Sociología por El Colegio de México, México. Colaboradora en la Asociación para el Avance de las Ciencias Sociales en Guatemala (AVANCSO), Guatemala, e integrante del Instituto de Investigación para la Incidencia en Educación y Formación Docente-EDUCA Guatemala. Temas de especialización: estudios de juventud y sociología de los mercados laborales. Correo electrónico: lemus.leslie@gmail.com.

Enviado a dictamen: 8 de enero de 2018

Aprobación: 28 de abril de 2018

Revisiones: 2 


\section{Introducción}

G uatemala es un país con una cruenta historia de violencia. Desde el derrocamiento del gobierno de Jacobo Árbenz en 1954, élites económicas y militares, contando con el apoyo y el financiamiento principalmente de Estados Unidos, tomaron el control del Estado y gestaron uno de los episodios más largos y brutales de violencia política en la historia de América Latina. La cúspide de esos procesos fueron las campañas genocidas que, desde una lógica contrainsurgente y empleando como fuente de legitimación el discurso anticomunista, se llevaron a cabo a finales de la década de los setenta e inicios de los ochenta del siglo XX (Taracena, 2004). ${ }^{1}$

Pero los tiempos cambiaron, la transformación del modelo económico y el auge de la democracia en el mundo demandaron la adaptación de las sociedades centroamericanas. Así es que, en Guatemala, desde mediados de la década de los ochenta se impulsaron procesos de transición política que incluyeron elecciones libres de gobiernos civiles y nuevas bases institucionales a partir de la Constitución. El proceso se consumó en 1996 con la firma de los Acuerdos de Paz.

Este escenario, que comenzó a configurarse desde los ochenta, generó las condiciones para la aplicación de políticas de ajuste estructural que implicaron la reducción del aparato burocrático, la privatización de servicios y la descentralización de las instituciones públicas (González-Izás, 2012; PNUD, 2010). Con estas medidas el país se alineaba a una agenda regional que ha apuntado a la creación de condiciones para la liberalización económica y la inversión extranjera, y en la que se han priorizado ciertas políticas de seguridad (Morales, 2007). ${ }^{2}$

En consideración de González-Izás, la forma en que fueron operados estos cambios y en que se produjo la incorporación de los antiguos actores de la contrainsurgencia a la nueva institucionalidad estatal en el territorio guarda relación directa con lo que nombra como "la actual geografía de la violencia" (González-Izás, 2015: 38).
Es decir, si bien la violencia ha sido un elemento constitutivo de las relaciones sociales y de la configuración del Estado guatemalteco desde sus orígenes, la centralidad y las características que ha cobrado el fenómeno en las últimas dos décadas tiene sus orígenes en el pasado reciente del país. No obstante, se ha nombrado y colocado como los principales protagonistas y responsables de ésta a cierto tipo de sujetos: jóvenes varones de zonas urbanas y provenientes de sectores populares. Aunque tales explicaciones se basan en datos y evidencias empíricas, éstas quizá sólo reflejan el resultado social de un proceso de raíces más complejas.

Partiendo de las consideraciones precedentes, el objeto de este texto es proponer algunos elementos para repensar el vínculo entre juventud y violencia en la Guatemala actual. Las reflexiones expuestas se derivan de una trayectoria de investigación que incluye experiencias de trabajo de campo en zonas urbanas de Ciudad Guatemala y otras regiones del país en distintos momentos desde 2002 hasta 2014, así como la participación en estudios dedicados al análisis de la producción de imágenes y discursos sobre juventudes. Las referencias empíricas citadas provienen de los documentos generados individual y colectivamente en ese marco. Asimismo, se ha realizado una revisión del corpus bibliográfico especializado en el tema para Guatemala, y se citan textos centrales en la discusión que sirven para situar o discutir los argumentos que aquí se plantean.

Esteartículocontieneuna seriedeproblematizaciones que apuntan a posicionar una discusión acerca de la necesidad de redefinir la agenda política y de investigación sobre violencia juvenil, así como a aportar elementos para la construcción de nuevas hipótesis y la renovación de las perspectivas de interpretación sobre el tema desde el caso guatemalteco.

\section{Discursos e intervenciones sobre violencia juvenil en Guatemala}

Una de las explicaciones privilegiadas para analizar los problemas contemporáneos de inseguridad son las llamadas youth bulge thesis, de acuerdo con las cuales 
se considera como factor de riesgo de violencia y criminalidad el crecimiento de la cohorte de personas de entre 15 y 24 años de edad, que representa más del 20\% de la población en contextos de pobreza (Kurtenbach, 2012: 5).

El caso guatemalteco tiende a confirmar esta tendencia. Así, en consecutivas mediciones se ha mostrado que las tasas de mortalidad violenta tienden a duplicarse en la población joven respecto de las mediciones generales, y representan al menos una tercera parte de este tipo de incidentes con respecto al total del país. Asimismo, ocurre que cerca de dos terceras partes de los perpetradores de actos delictivos son jóvenes varones (PNUD, 2007 y 2012; Waiselfisz, 2008). ${ }^{3}$

A partir de esta evidencia se han producido discursos que legitiman las intervenciones de distintos actores y las políticas públicas de seguridad desde finales de la década de los noventa del siglo XX hasta inicios del XXI. Para efectos de análisis, aquí se han identificado tres posiciones de enunciación e intervención: criminalización, prevención y crítica de la estigmatización.

Sostengo que, a pesar de su aparente diferencia u oposición, estas perspectivas tienen rasgos comunes. En primera instancia, hacen referencia a sujetos urbanos de sectores populares y estratos bajos, es decir, se enfocan en un perfil específico. Luego, asocian la violencia que involucra a estos jóvenes en términos de factores de riesgo y en clave de carencias que padecen como individuos. Además, comparten una imagen ideal acerca de cómo deberían ser las personas jóvenes - responsables, optimistas, creativos, productivos, propositivos, emprendedores, trabajadores, buenos ciudadanos y guatemaltecos-. Se trata del prototipo del "buen joven" que se porta bien y no crea problemas (Lemus, 2013).

\section{Criminalización y políticas de "mano dura"}

El núcleo central de los discursos de criminalización parte de que ciertas agrupaciones típicamente juveniles, las maras, son las principales responsables de la inseguridad ciudadana. ${ }^{4}$ Se atribuye a sus integrantes rasgos de desviación social y carencia moral: son intrínsecamente malos, inadaptados que violan las reglas, impulsivos e incontrolables, sin empatía en tanto se dedican a hacer daño a otras personas y a sus bienes. Se les considera seres improductivos porque no trabajan y, para obtener lo que desean, roban, asaltan, extorsionan y matan. Desde este tipo de argumentación se justifican y fundamentan distintas intervenciones.

Por un lado, se ponen en práctica acciones con lógica de "penalización" tales como las políticas de "mano dura" y leyes "antimaras". Éstas fueron promovidas con mucho entusiasmo en los países del norte de Centroamérica durante la primera década del siglo XXI, especialmente en períodos electorales como estrategia de capitalización de votos, considerando que es un razonamiento que tiene asidero en el sentido común y la experiencia cotidiana, además de que goza de amplia difusión mediática. En el caso de Guatemala, aunque las iniciativas de ley no han sido aprobadas, sí se han ejecutado campañas de seguridad y detenciones bajo estos parámetros (Merino, 2004). ${ }^{5}$

Los principales rasgos de este tipo de intervenciones han sido: penalizar el hecho del agrupamiento y convertir en figura jurídica una categoría social - la mara-, atribuir pertenencia por razones de aspecto vestimenta y tatuajes-, apresar sin probar comisión de delito - la pertenencia al grupo sería el nuevo delito-o establecer excepciones al debido proceso en caso de acusaciones a integrantes - reales o supuestos - de estos grupos, incluyendo la anulación de medidas sustitutivas. Debe enfatizarse que, en contra del espíritu de la justicia penal, estas medidas tienden a la arbitrariedad pues se sustentan en percepciones y no en pruebas o testimonios de hechos. ${ }^{6}$

Por otra parte, la expresión extrema en la que se concretan estos argumentos de criminalización es la llamada "limpieza social"? Estas prácticas tienen sus antecedentes en la contrainsurgencia del período histórico previo, pero se mantienen vigentes: tortura, logística de secuestro, asesinato y traslado de cadáveres (Sanford, 2008: 29). Éstas suelen ser acciones llevadas a cabo por actores al margen de la ley — paramilitares 
o escuadrones de la muerte- que cuentan con la aprobación o tolerancia del Estado, e incluso en algunos casos con la participación directa de agentes estatales.

Para justificar y encubrir la práctica de ejecuciones extrajudiciales, se suele atribuir a las víctimas el pertenecer a pandillas — como en el pasado inmediato lo fue la acusación "subversivos"-. A continuación, a través de medios de comunicación masiva se divulga el argumento de que son los propios integrantes de estos grupos los que comenten asesinatos por rivalidad de territorios, competencia criminal o castigo por traición (Sanford, 2008; Escobar, 2003). Es decir, desde esta mirada, las personas jóvenes no sólo ejercen la violencia que afecta a la sociedad en general, sino la que ellos mismos reciben.

\section{Prevención de la violencia juvenil}

Los discursos de prevención de violencia juvenil comparten con los de criminalización el diagnóstico del problema, pero apuntan a una explicación más compleja. Reconocen la existencia de jóvenes que cometen delitos o son violentos, pero tienden a situarlos como sujetos vulnerables. Así, atribuyen la causa de sus conductas a distintos factores - pobreza, falta de oportunidades educativas y de empleo- o carencias -familia, autoestima o alienación cultural- que de ser modificados o compensados permitirían su incorporación plena a la sociedad.

El modelo básico de intervención que se ha derivado de estos razonamientos aborda la violencia como un asunto de salud pública en el que actúan factores de riesgo y protección; por tanto, se intenta potenciar los segundos para neutralizar los primeros (Rodríguez, 2011). De esa cuenta, los programas desarrollados han contemplado atención psicológica y psicosocial, como el fortalecimiento de los vínculos familiares de afecto, formación en valores, y creación de redes de apoyo social e institucional, como los comités de prevención del delito integrados por miembros de las comunidades o barrios en los que se ejecutan los proyectos. Se han implementado medidas de estímulo educativo e inserción laboral tales como becas para estudio para el sistema formal y capacitación para el trabajo, apoyo en búsqueda de empleo o fomento de microempresas. Asimismo, se han incorporado componentes de recreación - formación y creación artística, actividades y espacios lúdicos-. ${ }^{8}$

El carácter benevolente de los planteamientos de prevención ha sido atractivo para una diversidad de actores: desde las organizaciones juveniles y los programas o proyectos estatales y de sociedad civil dirigidos a jóvenes, hasta los organismos de cooperación internacional. Las acciones que éstos han llevado a cabo se sitúan como alternativas a la criminalización, y han llegado incluso a competir por la definición de la política pública oficial; no tanto por sus resultados, porque no hay evaluaciones o mediciones de impacto, sino porque son afines al espíritu democrático y de derechos humanos a los que se adscriben estos actores. ${ }^{9}$

Debe anotarse que este tipo de abordaje ha cambiado con el tiempo. En un primer momento buscaban trabajar con dos tipos de población: por un lado, con quienes ya estaban involucrados en maras, incluso si se encontraban en presidios, y, por el otro, con quienes, aunque no formaban parte de estos grupos, residían en contextos en los que sí existían y, por tanto, eran considerados "jóvenes en riesgo". Con los primeros la labor era llamada de "reinserción" y, con los segundos, de "prevención" (Merino, 2004; Hun, Lemus y Monzón, 2006).

En años recientes las acciones de intervención se han decantado por la prevención. La renuncia a los propósitos de reinserción social está relacionada con los cambios experimentados en el fenómeno de la violencia que involucra a personas jóvenes. Ésta se ha exacerbado de modo tal que muchos territorios urbanos se han vuelto inaccesibles, incluso miles de habitantes de los barrios han sido desplazados de sus residencias y se han visto forzados a migrar a otros sitios dentro y fuera del país (AESU, 2014; ACNUR, 2016).

También ocurre que el fracaso de las anteriores estrategias ha conllevado frustraciones para quienes estaban "rehabilitándose" — problemas de acceso y permanencia en el empleo, la quiebra financiera de los microemprendimientos y la inestabilidad de las redes sociales e institucionales concebidas para la facilitación 
del proceso-,${ }^{10}$ por lo que llegaron incluso a reincidir en acciones delictivas (Lemus, 2013; AESU, 2014). Las instancias que han mantenido una línea de trabajo de reinserción son las Iglesias cristiano-evangélicas bajo la lógica de la conversión religiosa, lo que ha sido posible por la legitimidad de la que gozan este tipo de expresiones organizativas en la sociedad guatemalteca (Dary, 2013; Castillo, 2016).

\section{"Ser joven no es un delito": los argumentos contra la estigmatización}

Los discursos y prácticas de criminalización han suscitado preocupación en actores que no comparten este tipo de abordajes, tales como las organizaciones de derechos humanos, o que intervienen en la política pública desde perspectivas de seguridad democrática. ${ }^{11}$

El objetivo central de los discursos que producen es denunciar la violencia y discriminación hacia los jóvenes que por su aspecto — vestimenta o fenotipo, por ejemplo - o el lugar donde residen — barrios marginados, considerados áreas peligrosas o "zonas rojas" - son sistemáticamente estigmatizados. Incluso, algunas de estas instancias han señalado que muchas de las acusaciones pesan sobre quienes no están involucrados en maras ni en actividades criminales o violentas (Lemus, 2013).

A partir de estos argumentos se han realizado investigaciones sobre el patrón de ejecuciones extrajudiciales y acoso por parte de las fuerzas de seguridad del Estado y grupos paraestatales (Samayoa, 2007; Flores y Joaquín, 2013). También se han encaminado indagaciones sobre las percepciones que la población tiene de estos jóvenes y se han realizado campañas de sensibilización sobre la estigmatización de la que son objeto (López y Samayoa, 2009). ${ }^{12}$ Destacan también algunos esfuerzos — acotados y limitados en tiempo - por ofrecer a las mujeres y hombres jóvenes procesos de formación en estas áreas que les permitan contar con herramientas para su propia defensa, seguridad y protección. ${ }^{13}$

En suma, se trata de un abordaje que, desde la perspectiva doctrinaria de derechos humanos, ha sido construido para enfrentar y contestar de manera directa las visiones dominantes sobre la violencia en la que están involucradas personas jóvenes, pero que, en sentido estricto, no constituye una reformulación de la problemática (Rodríguez, 2011: 29).

Elementos y aportes para la reinterpretación del vínculo entre juventud y violencia en la Guatemala contemporánea

Las formas como las sociedades definen y tratan los problemas están demarcadas por límites simbólicos, discursivos y comprensivos que conducen a enfocarse en ciertos temas, en ciertas maneras de actuación, y con determinadas categorías que se convierten en dominantes y restringen nuestros marcos de visión (Bourdieu, 1972 y 2000).

En el caso del vínculo entre juventud y violencia, las formas en que éste ha sido abordado en Guatemala permiten establecer relaciones entre unos ciertos elementos del contexto y no entre otros, como ha sido ilustrado en la exposición del apartado anterior. En esta segunda parte del texto se exponen algunos elementos que apuntan a la reinterpretación del fenómeno (Lemus, 2013).

\section{Aproximaciones históricas y análisis situados: el caso de las maras}

Como he señalado antes, las maras han sido el tópico privilegiado de la discusión sobre violencias juveniles en Guatemala. No quiere decir que sea el único, pero la relevancia que ha tenido en la construcción de las representaciones sobre el tema hace que sea necesario dedicar un espacio a reflexionar de manera específica.

Las maras tienen un origen y una historia. Estas agrupaciones se han transformado desde sus inicios hasta la actualidad, de lo que dan cuenta diversas investigaciones realizadas en distintos momentos. Así, cuando a finales de la década de los ochenta Deborah Levenson se aproximó a éstas en el trabajo fundante Por sí mismos (1988), se encontró con jóvenes — hombres y mujeres - cuya experiencia de vida en la ciudad estaba 
marcada por la pobreza, el deterioro de la educación pública y la novedosa influencia de los medios de comunicación masiva y de los productos culturales que transmitían - películas, música rap y breakdance - que sumaron la presión por el consumo de determinados símbolos y estética — ropa, calzado o discos, entre otros elementos-. Fueron etiquetados como violentos por el gobierno, reprimidos con la misma brutalidad que a los movimientos sociales, y descalificados por distintos sectores políticos -incluidas las expresiones de izquierda-. ${ }^{14}$ Constituían una nueva forma de colectividad que contenía las frustraciones, aspiraciones y la búsqueda de pertenencia de un grupo social y generacional excluido. Es importante señalar que para elaborar esta caracterización Levenson recurrió principalmente a las voces de sus miembros — aún era posible acercarse y hablar con ellos y ellas-, las cuales contrastó con las de otros actores del gobierno, la prensa y organizaciones no gubernamentales que realizaban trabajo con niñez en situación de calle, entre otras instancias.

En la década de los noventa, cuando Juan Merino (2001) retomó la investigación sobre las maras encontró un panorama más complejo. Grupos con una estructura jerárquica, códigos de lealtad e identidad, reglas internas y de relacionamiento con otros miembros de sus barrios, disputas cada vez más sanguinarias por sus territorios frente a otras maras y, por supuesto, la comisión de delitos de tipo económico — robos especialmenteEste autor trata en su estudio de argumentar en favor de una hipótesis: las maras constituyen una transformación de la resistencia social en un contexto de desarticulación política, su evolución violenta se debe a la ruptura de los lazos sociales a partir del conflicto armado reciente, y su propensión a cometer cierto tipo de delitos responde a la exclusión social de los jóvenes - falta de oportunidades educativas y laborales- L La reconstrucción elaborada por Merino se sirve de una multiplicidad de fuentes que incluyen testimonios de expandilleros, pero no de miembros activos.

En años recientes Levenson (2013) retomó el análisis sobre las maras en Guatemala y se encontró con un escenario aún más brutal. Los crímenes predominantes son el asesinato - con tales niveles de crueldad que incluso llegan a la mutilación del cuerpo-, la extorsión - con amenaza de muerte incluida - y el reclutamiento de miembros aún más jóvenes, incluso niños. Las maras transitaron de proteger sus barrios, a abusar de éstos; de formar parte de ellos, a constituir una amenaza constante. Por supuesto, en esta ocasión los sujetos no son accesibles —están muertos, encarcelados o son temidos-. ${ }^{15}$

Muchos de los estudios sobre el origen y desarrollo de las maras dan cuenta de una transformación, de espacios de sociabilidad juvenil a complejas redes criminales. En ellos se han privilegiado explicaciones que enfatizan dimensiones macro tales como el impacto de las migraciones y las deportaciones, el fin del conflicto armado interno, la influencia cultural de los medios de comunicación masiva y la exclusión social (Merino, 2001, 2004 y 2007; Savenije, 2009). Sin duda, éstos son factores por considerar, pero es necesario indagar sobre cómo se articulan con los contextos locales (González-Izás, 2015). En ese sentido, Levenson (2013) propone analizar el fenómeno de manera relacional a escala transnacional, nacional y local.

Siguiendo los razonamientos de las autoras citadas, propongo que, para comprender la evolución de las maras en el caso de Guatemala, es necesario examinar el reposicionamiento de actores económicos y militares, cómo se redefinió el territorio centroamericano en términos geopolíticos y geoeconómicos a partir de los procesos de transición desde la década de los ochenta, y las actividades de lucro que proliferaron desde entonces - tráfico de drogas, personas o armas, entre otros negocios-.

Es decir, las maras no son algo ajeno o aislado del conjunto de la sociedad guatemalteca, por tanto, es necesario pensar la trayectoria de este fenómeno en relación con la historia reciente del país, con la configuración de las relaciones y arreglos sociales. Para ello es necesario desmarcarse de los grandes relatos que se han construido al respecto y profundizar en la investigación situada que permita entender sus rasgos actuales (ver Imagen 1). 
Jerarquías sociales y generacionales

En muchas ocasiones, la lógica con la que se narran los hechos de violencia actuales se plantea en términos de "jóvenes contra jóvenes", y de éstos contra la sociedad. ${ }^{16}$ Al respecto, Sabine Kurtenbach (2012), comparando los casos de Camboya y Guatemala, señala que no todas las sociedades posconflicto derivan en escenarios de violencia social como el que viven estos países, y que ello depende de los patrones de finalización de las guerras y de reconstrucción posterior. En particular, propone observar la interacción entre lo que llama "sociedad joven" y "sociedad adulta". ${ }^{17}$

En esos términos, la autora presta atención a varios elementos que caracterizan a estas sociedades. Encuentra que las formas de socialización tienen componentes de violencia heredados históricamente, que las condiciones de transición a la vida adulta plantean dificultades para lograr la independencia económica, que los espacios de participación están limitados o cerrados para los jóvenes y que la rigidez de la estructura social impide la movilidad a la que podrían aspirar. En su interpretación, lo anterior ha configurado conflictos actuales de orden generacional. Adicionalmente, plantea que las estructuras armadas que cobraron protagonismo en las posguerras, y en las que participan jóvenes, son controladas por adultos.

Estas explicaciones son plausibles si se examinan casos concretos. Por ejemplo, el estudio realizado por el equipo del Área de Estudios Socio-Urbanos (AESU) de la Asociación para el Avance de las Ciencias Sociales en Guatemala (AVANCSO) durante 2013 y 2014 en barrios del norte de Ciudad Guatemala ofrece algunos elementos que ilustran lo anterior. Así, en este trabajo presentan el caso de pandilleros que alguna vez sirvieron a determinada estructura, pero cuando resultaron molestos o incómodos fueron eliminados:

[...] en el B* en 2005 todavía había algunos 18, no sé si alguna vez estuvieron unidos con los del $\mathrm{P}^{*}$ porque éstos fueron muertos, pero una vez los invitó a jugar fútbol un tipo que dicen era guardaespaldas de alguien de un partido político —que hasta el nombre le habían puesto al equipo- - y luego todos aparecen muertos itodos, todos, todos, todos aparecen muertos! (entrevista a AG, 4 de septiembre de 2013, citada en AESU, 2014).

El testimonio de una joven mujer, pareja de un marero, ilustra cómo se entretejen las jerarquías sociales y generacionales que plantea Kurtenbach:

[...] al principio sólo le hacía favores a la mara, pero ya cuando nació el bebé se integró totalmente [...] trabajaba en una fábrica pero lo dejó, creo que la mara lo obligó para que se hiciera cargo [...] lo mataron en 2010 , ya no vivía aquí sino en una casa en residencial ${ }^{18}$ con otros, nosotros lo íbamos a ver [...] a la casa llegaban niños como de 12 o 13 años, sacaban el arma y la ponían en la mesa cuando les daba de comer. Cuando les preguntaba por qué lo hacían me decían: "esa es la vida que nos tocó vivir", varios ya están muertos (entrevista a OL, 19 de enero de 2014, citada en AESU, 2014).

En suma, lo que aquí se plantea es que un elemento a tener en cuenta es cómo, en las organizaciones criminales, los jóvenes son responsables de materializar los crímenes, pero no son quienes toman las decisiones. La violencia juvenil será inteligible a partir de establecer su relación con el resto de la sociedad e identificar las posiciones que estos sujetos ocupan en los esquemas de poder.

\section{Los "no violentos"}

Los estigmas que pesan sobre los jóvenes de sectores populares tienen manifestaciones e implicaciones concretas. Quienes habitan en sectores de la capital guatemalteca considerados como "zonas rojas" y peligrosas deben enfrentar a diario el acoso violento de las fuerzas de seguridad o la amenaza de ejecuciones extrajudiciales, e incluso asumir la etiqueta de "en riesgo". Lo cierto es que su vida es compleja y en ella se entretejen lógicas de violencia y delito con otras más constructivas o colaborativas. 
Así, es posible encontrar historias de jóvenes que nunca se han involucrado en la comisión de delitos o actos de violencia, pero conviven con otros que sí, los conocen y han crecido juntos. Y aun esos jóvenes que serían considerados "violentos" tienen facetas en sus vidas en las que eso no predomina:

[...] lo balearon y ahora está en el intensivo, yo le tengo cariño porque conmigo ha sido buena gente, pero toma mucho, maneja un tuc tuc ${ }^{19} \mathrm{y}$ siempre me hace el servicio del mercado para acá [...]; yo le digo a mis hijos que tienen que conocer la vida, se tienen que relacionar con todo mundo y también con mareros, para saber comportarse bien (entrevista a EA, 13 de octubre de 2013, citada en AESU, 2014).

Importante de apuntar es que en estos sectores sociales existen personas jóvenes que no están involucradas en organizaciones criminales, y antes bien padecen la violencia que éstas ejercen en los territorios en donde viven:

La mayor parte de veces les pasan cosas no porque estén metidos en algo sino porque estaban en el lugar equivocado [...] la mayoría están estudiando y no quieren problemas [...]; a mis hijos les he inculcado la dedicación a tratar de llevar bien la vida y mostrarles que involucrarse en esas cosas conlleva 90\% más de riesgo que de placer (entrevista a CA, 13 de octubre de 2013, citada en AESU, 2014).

Adentrarse en las biografías y experiencias aportaría a la comprensión de la complejidad de la violencia actual y a deconstruir las imágenes dominantes sobre las personas jóvenes que viven o provienen de estos contextos, así como también permitiría identificar los factores, decisiones y recursos que conducen sus trayectorias en distintas direcciones.

\section{La violencia de los jóvenes de estratos medios y altos}

Otro elemento importante para incorporar en la reinterpretación del vínculo entre juventud y violencia en Guatemala es la violencia ejercida por jóvenes de estratos medios y altos, difundida y analizada en menor medida que la cometida por jóvenes de sectores populares.

Por ejemplo, según ha documentado Gabriela Escobar (2005), en la década de los noventa la capital guatemalteca era escenario de violentos enfrentamientos entre jóvenes de sectores populares - los breaks y estudiantes de institutos públicos-y de sectores medios o altos - los antibreaks o "burgueses", estudiantes de escuelas privadas-. Estos últimos se organizaban en grupos, liderados por hijos de figuras connotadas de la contrainsurgencia y el anticomunismo, para salir de "cacería" tras los primeros. Estas persecuciones tenían incluso saldos fatales:

Se llamaba M., era 18, que en ese entonces no era tan grueso. Un día en el centro los empezaron a perseguir y él se cayó, lo dejaron allí por salir huyendo y lo empezaron a "verguiar"20 por todo el cuerpo, le dieron en la cabeza con bates. Se murió, allí quedó muerto (entrevista a RC, 13 de septiembre de 2013, citado en AESU, 2014).

En épocas más recientes han surgido manifestaciones violentas que quizá son menos explícitas en su justificación clasista, pero son igual de cruentas en su ejercicio. Por ejemplo, Stephanie López (2012) reconstruye un caso de vapuleo llevado a cabo por estudiantes a las afueras de una universidad privada en Ciudad Guatemala. Quienes fueron objeto del acto eran jóvenes procedentes de las comunidades vecinas al campus - colonias populares - acusados de cometer robo. Ninguno de los participantes y observadores que López entrevistó tenía certeza de quién era la víctima y de si los supuestos asaltantes eran tales. La autora explora las justificaciones de esta acción y encuentra detrás de éstas una lógica común: se trata de chivos expiatorios, aquellos que deben pagar por los agravios de los que este grupo de universitarios se han sentido víctimas — violencia delincuencial en especial—.

No se trata simplemente de afirmar que los jóvenes de estratos medios y altos también son o pueden ser 
violentos. Detrás de estos actos subyace un conflicto social amplio que se expresa generacionalmente. Los casos citados evidencian una asimetría económica y de poder entre quienes perpetran violencia o son objeto de ella.

Las acciones descritas son indicativas de la necesidad que tienen estos jóvenes de sectores medios y altos de mantener, a toda costa, la distancia social con un "otro" que resulta amenazante - los pobres, "indios", "shumos" ${ }^{21}$ " "mareros"-(Garcés, 2003). ${ }^{22}$ Tan endeble es el vínculo entre unos y otros, y tan grande el abismo de la distancia que los separa, pero también la precariedad de los mecanismos que sostienen esta desigualdad, que incluso es posible llegar a la eliminación física del "otro" con tal de mantenerla.

\section{Reflexiones finales}

El argumento que se presenta en este texto es que para comprender el vínculo entre violencia y juventud es necesario indagar en algo más que sus manifestaciones y profundizar en las relaciones que las producen. En este sentido, se plantean cuatro elementos a introducir en el análisis del caso guatemalteco, los cuales han sido débilmente considerados por las perspectivas predominantes en el abordaje del tema de la violencia juvenil.

En primer lugar, dada la centralidad del fenómeno de las maras en el país, se propone reconstruir su desarrollo y establecer nexos entre procesos sociales a escala transnacional, nacional y local que involucran a la diversidad de actores. En segundo lugar, se ha señalado la necesidad de analizar las jerarquías sociales y generacionales que configuran el ejercicio de determinadas formas de violencia en el contexto posconflicto, especialmente criminales, y en las que las personas jóvenes generalmente ocupan posiciones subordinadas.

También, como tercer elemento, se señala que es importante evidenciar los aspectos no violentos de las vidas y trayectorias juveniles, aun en escenarios de violencia. Este acercamiento permitiría desmitificar el vínculo al que aquí nos referimos y ofrecería indicios sobre las alternativas y recursos con que cuentan, así como sobre las estrategias que desarrollan los sujetos juveniles para enfrentar estos escenarios adversos.

Finalmente, como cuarto elemento, se sitúa la mirada sobre las violencias que ejercen jóvenes de estratos medios y altos, por un lado, para cuestionar la correspondencia que suele establecerse entre pobreza y violencia, $y$, por el otro, para identificar los conflictos y las desigualdades sociales que subyacen en ellas.

En suma, la violencia ejercida y vivida por las personas jóvenes es resultado de formas concretas de estructuración de las sociedades. La reinterpretación por la que se apuesta y los elementos planteados en este texto constituyen una propuesta para continuar la discusión y profundizar en la investigación desde perspectivas procesuales y relacionales que consideren las especificidades contextuales en el análisis del fenómeno.

\section{Notas}

' El informe Guatemala, memoria del silencio de la Comisión para el Esclarecimiento Histórico (CEH) reporta que entre 1960 y 1996 fueron desaparecidas 45000 personas, asesinadas otras 250000 y cerca de un millón tuvieron que desplazarse de los territorios que habitaban algunos se refugiaron en territorio mexicano o trataron de sobrevivir internándose en selvas y montañas, otros migraron a los principales centros urbanos del paísEn el período de 1978 a 1982 fueron cometidas más de 400 masacres en comunidades mayoritariamente indígenas. El balance es que el 97\% de las violaciones a derechos humanos durante este período son responsabilidad de las fuerzas armadas del Estado guatemalteco.

2 Estados Unidos es el país con mayores aportaciones de cooperación bilateral en Guatemala y la agenda que impulsa está asociada a políticas de seguridad hemisférica. Por ejemplo, en los últimos tres lustros la Agencia de los Estados Unidos para el Desarrollo (USAID por sus siglas en inglés) ha sido una de las fuentes más importantes para el financiamiento de proyectos de prevención de violencia juvenil.

${ }^{3}$ El rango etario utilizado en las distintas fuentes varía debido a que consideran parámetros diferentes para la 
definición de la categoría "joven", van desde los 13 a los 29 años de edad. Lo relevante para este argumento es que se construyen imágenes, discursos y representaciones en torno a las personas jóvenes, y es lo que aquí se intenta mostrar.

${ }^{4}$ Ejemplo de ello es el caso documentado por el periodista Lafitte Fernández (2011) acerca del asesinato en territorio guatemalteco de un grupo de diputados salvadoreños del Parlamento Centroamericano (PARLACEN) en 2008. Las autoridades responsables de seguridad pública atribuyeron la participación en la cadena de hechos relacionados con el crimen a miembros de la Mara Salvatrucha. También el caso del pandillero Áxel Danilo Ramírez Espinoza —apodado Smiley-, que en distintas ocasiones desde 2009 ha sido acusado de dirigir redes de extorsión y sicariato (Patzán y Sánchez, 2016).

${ }^{5}$ Es el caso del Plan Escoba ejecutado por el Ministerio de Gobernación (MINGOB) en 2003 o la aplicación de estados de excepción en localidades urbano-populares de Ciudad Guatemala en 2012 con la intervención de fuerzas combinadas de policía y ejército. Leyes antimaras o antipandillas fueron aprobadas en Honduras en 2003 y en El Salvador en 2010. En el caso de Guatemala, en el año 2012 fue impulsada una iniciativa de reforma al Código Civil para redefinir la mayoría de edad a los 12 años y así imputar delitos a quienes superen ese parámetro; el cambio legal no se produjo. El ponente fue el militar retirado Otto Pérez Molina, entonces presidente del país y actualmente encarcelado por delitos de corrupción (Castañón, 2012).

${ }^{6}$ Los derechos civiles y políticos vigentes establecen la libertad de asociación y organización, en tanto el Código Penal establece castigos por la comisión de delitos y no por la pertenencia a algún grupo en particular.

${ }^{7}$ El término ha sido utilizado para referirse al mecanismo de represión, selectivo o indiscriminado, dirigido hacia individuos o grupos considerados indeseables con el objetivo de intimidarlos o exterminarlos, y que es ejercido por agentes armados. Su uso ha sido criticado por algunos analistas con el argumento de que es un eufemismo de la impunidad de estos actos. En el texto se decide conservarlo para caracterizar el discurso que fundamenta la práctica de ejecuciones extrajudiciales. El ejemplo paradigmático de este tipo de violencia estatal en el contexto posconflicto fue el gobierno de Óscar Berger (2004-2008), candidato del partido de derecha Gran Alianza Nacional. Durante ese período, la "limpieza social" fue sistemáticamente empleada y dirigida desde los órganos de seguridad pública, de tal cuenta que los funcionarios de esa gestión: Carlos Vielman, ministro de Gobernación, Erwin Sperinsen, director de la Policía Nacional Civil, y Alejandro Giammattei, director del Sistema Penal, han enfrentado procesos en tribunales nacionales e internacionales por ejecuciones extrajudiciales.

${ }^{8}$ El hito en este ámbito de acción lo constituyó el surgimiento de la Alianza para la Prevención del Delito (APREDE) fundada en 2001 con participación de instancias gubernamentales y organizaciones no gubernamentales. Estuvo conformada por la Asociación Multisectorial Penitenciaria Guatemalteca (AMPEGUA), Familiares y Amigos Víctimas de la Delincuencia y el Secuestro (FADS), el Instituto de Estudios Comparados en Ciencias Penales de Guatemala (ICCPG) y el Centro de Acción Legal en Derechos Humanos (CALDH); asimismo, albergó programas de la Secretaría de Bienestar Social de la Presidencia (SBSP). Esta experiencia fue financiada por la USAID a través de la agencia Creative Associates Internacional, Inc. (CAII). Desde comienzos de esa década han sido implementados numerosos proyectos de prevención de la violencia juvenil que en líneas generales han seguido este modelo. Según el caso, hicieron énfasis en algunos elementos más que en otros. La mayoría fueron ejecutados en la zona metropolitana del departamento de Guatemala, pero cuando tuvieron proyección nacional establecieron sedes, proyectos subsidiarios o adaptaciones locales en distintas partes de país.

${ }^{9}$ En el gobierno de Óscar Berger (2004-2008) APREDE y otras organizaciones firmaron un convenio con el MINGOB para implementar un proyecto piloto de prevención. En este mismo período fue emitida la Política Nacional de Prevención de la Violencia Juvenil. En el gobierno de Álvaro Colom (2008- 
2012) fue implementado, en el marco del conjunto de política social, el Programa Presidencial Escuelas Abiertas con un enfoque que involucraba a la comunidad. En los inicios del gobierno de Otto Pérez Molina (2012-2016) el tercer viceministerio de Apoyo Comunitario del MINGOB convocó a una serie de consultas para la formulación de la Política contra la Violencia Juvenil, pero el proceso no fue concluido. Asimismo, existen tres versiones de la Política Nacional de Juventud (2005-2015, 2010-2015 y 2012 2020) que corresponden a los tres gobiernos de esos períodos. Con el tiempo ha cambiado el hecho de que la sociedad civil organizada sea la principal impulsora de estas iniciativas, cuestión que ha sido asumida por diversas agencias gubernamentales. El rasgo común en cada uno de estos procesos y momentos ha sido la presencia de USAID.

10 Este modelo de intervención ha enfatizado el desarrollo de capacidades y habilidades individuales, en tanto los sujetos se insertan en una estructura social excluyente. Así, las capacitaciones para el empleo se enfrentan con el hecho de que los mercados laborales se han flexibilizado, su regulación es precaria y el desempleo tiende a ser de larga duración. Los microemprendimientos, en un contexto en el que las oportunidades de acumulación de capital están concentradas, acaban por sumarse a muchas otras formas de economía de subsistencia. Además, estos procesos han sido acotados en tiempo, recursos y población beneficiaria; en la medida que no se han logrado institucionalizar, han dejado a la deriva a los involucrados cuando finalizan.

${ }^{11}$ Según el Tratado Marco de Seguridad Democrática en Centroamérica: “[...] se sustenta en la supremacía y el fortalecimiento del poder civil, el balance razonable de fuerzas, la seguridad de las personas y de sus bienes, la superación de la pobreza y de la pobreza extrema, la promoción del desarrollo sostenible, la protección del medio ambiente, la erradicación de la violencia, la corrupción, la impunidad, el terrorismo, la narcoactividad, el tráfico de armas. Asimismo, el Modelo Centroamericano de Seguridad Democrática orientará cada vez más, sus recursos a la inversión social" (Consejo Permanente de la Organización de Estados Americanos, 1995).

12 En esta línea, en 2010 fue lanzada una campaña liderada por CALDH y apoyada por distintas organizaciones de jóvenes y derechos humanos. La consigna principal de ésta era: "Ser joven no es un delito". En ese marco se llevó a cabo una estrategia con medios de comunicación - conferencias de prensa, producción y promoción del video-clip musical "Somos juventud"-, actividades públicas — conversatorios, festivales artísticos- y una serie de artículos visuales —camisetas, stickers, posters-.

${ }^{13}$ Es el caso del acompañamiento que la Unidad de Protección a Defensoras y Defensores de Derechos Humanos-Guatemala (UDEFEGUA) brindó a distintas organizaciones de y para jóvenes dedicadas al arte y la recuperación de espacios públicos para la conformación de una red de protección especializada; el hito que marcó esta iniciativa fue el asesinato de Víctor Leiva, miembro del colectivo artístico Caja Lúdica, en 2011. En esta clave puede incluirse el proyecto piloto de medidas sustitutivas en casos de faltas leves dentro del Programa Resolución Alternativa de Conflictos y Justicia Penal implementado por el ICCPG y cuya directriz fundamental es evitar la penalización e institucionalización de jóvenes en conflicto con la ley.

${ }^{14}$ Levenson (1998) documenta, a partir de distintos relatos y material hemerográfico, que la imagen del movimiento estudiantil de nivel medio empezó a mimetizarse con la de las maras. El gobierno les acusaba de saquear comercios y cometer actos vandálicos en el marco de protestas contra el alza al precio del pasaje en el transporte público, mientras los movimientos sociales afirmaban que eran grupos instrumentalizados por la inteligencia militar para infiltrarse en sus organizaciones.

${ }^{15}$ La autora toma posición y, frente a las afirmaciones que argumentan que la violencia de las maras es una suerte de anomia social — apolítica - , señala que tienen un uso político concreto - el miedo-, que permite actualizar formas de gobierno y control históricamente arraigadas en la sociedad guatemalteca. Para ello usa el término politics of death (políticas de muerte), tomando como 
referencia el concepto de "necropolítica" desarrollado por Achille Mbembe, en diálogo con el concepto de "biopolítica" de Foucault y ampliado por Agamben.

${ }^{16}$ Es una perspectiva que se reproduce en el abordaje de problemáticas que en distintos momentos han cobrado notoriedad por encima de los acostumbrados temas de violencia juvenil, tal es el caso del acoso escolar - bullying - o los suicidios en adolescentes. Abstrayendo las acciones de los sujetos de su contexto se les convierte en víctimas y victimarios. Algunos ejemplos a partir de revisión hemerográfica ilustran este argumento (Tejeda, 2011; Ortiz, 2012; Galeano, 2012; Lemus, 2012; Palma, 2012).

${ }^{17}$ El contrapunto en la región es el caso de Nicaragua. El enfrentamiento entre el gobierno sandinista y los grupos paramilitares de la "contra" ocurrió en temporalidades similares a los conflictos de Guatemala y El Salvador; sin embargo, una vez finalizado el proceso y hasta la actualidad no han proliferado las maras o pandillas como en estos dos últimos países.

${ }^{18}$ Las casas en "residencial" son conjuntos de viviendas o condominios cerrados, resguardados por seguridad privada y que constituyen los lugares de habitación de sectores medios y altos.

${ }^{19}$ Se refiere al tipo de transporte moto-taxi, utilizado para recorrer cortas distancias, con capacidad para transportar al conductor y máximo tres pasajeros, de motor y carrocería rústica.

${ }^{20}$ Término utilizado coloquialmente para referirse a la acción de golpear.

21 Es un término utilizado peyorativamente en Guatemala para referirse a aquellos que por su fenotipo son considerados indígenas, pero que no necesariamente se autoidentifican de esta manera. Además, son pobres, "corrientes", "sin cultura" y "sin clase". Existen estudios lingüísticos en los que se ha analizado el origen de esta categoría y otras sinónimas — "muco", "cholero"—. Un caso similar podría ser el término "naco" utilizado en México.

22 En este estudio, Cecilia Garcés explora el uso de categorías y estereotipos racistas con estudiantes de educación media de orígenes diversos. Encontró una asociación entre prejuicios raciales y de clase que se concretan en el estereotipo del marero: "En lo físico, los mareros son jóvenes, sucios, morenos y feos. Un estudiante explicó que: revelan odio en la mirada" (Garcés, 2003). Juan Merino, en 2001, hizo un ejercicio similar con estudiantes universitarios y encontró que éstos se posicionaban frente a las maras incluso como sus adversarios sociales y morales.

\section{Referencias}

ACNUR (Alto Comisionado de las Naciones Unidas para los Refugiados) (2016). Marco integral regional para la protección y soluciones. Disponible en: http://bit. ly/2Gbjm2n, consultado el 20 de julio de 2017.

AESU (Área de Estudios Socio-Urbanos) (2014). Prevención de la violencia-Guatemala: cambios y continuidades en las dinámicas de la violencia en las colonias del Puente Belice de Ciudad Guatemala: una mirada desde la experiencia de sus habitantes. Guatemala: AVANCSO. Disponible en:http://pdf.usaid.gov/pdf_docs/pa00kdsf.pdf, consultado el 20 de julio de 2017.

Bourdieu, Pierre (1972). Outline of a Theory of Practice. Nueva York: Cambridge University Press.

Bourdieu, Pierre (2000). Cosas dichas. Barcelona: Gedisa.

Castañón, Mariela (2012). "Bajarían mayoría de edad a doce años ante crímenes”. En La Hora, martes 13 de marzo. Disponible en: https://bit.ly/2rRJVRN

Castillo, Mynor David (2016). Influencia de la religión cristianaen ladisminución de la violencia juvenilen Guatemala. Guatemala: Universidad de San Carlos de Guatemala.

Comisión para el Esclarecimiento Histórico (1999). Guatemala, memoria del silencio: Informe. Guatemala: Comisión para el Esclarecimiento Histórico.

Consejo Permanente de la Organización de Estados Americanos, Comisión de Seguridad Hemisférica (1995). Tratado marco de seguridad democrática en Centroamérica, Disponible en: https://bit.ly/2IrrkCf.

Dary Fuentes, Claudia (2013). Las iglesias ante las violencias en Latinoamérica. Modelos y experiencias de paz en contextos de conflicto y violencia. CLALS Working Paper Series No. 3. Washington, D.C.: Center for Latin American \& Latino Studies - American University. Disponible en: https:// bit.ly/2u4MqUe (consultado el 20 de julio de 2017). 
Escobar Urrutia, Gabriela (2003). "Los jóvenes son noticia: la representación de la juventud en la prensa escrita". En Formación de líderes en pensamiento democrático. Guatemala: FLACSO.

Escobar Urrutia, Gabriela (2005). Enfrentamientos y violencias juveniles en la ciudad de Guatemala (1985-1993). Guatemala: Universidad de San Carlos.

Fernández, Laffite (2011). Crimen de Estado. El caso PARLACEN. San Salvador: AURA Ediciones.

Flores, Gabriela y Jorge Joaquín (2013). Ejecuciones extrajudiciales de jóvenes. Un delito de ayery de hoy. Guatemala: Centro para la Acción Legal en Derechos Humanos.

Galeano, Gladys (2012). "Envían a correccional a agresores de niño de 11 años". En El Periódico, martes 6 de marzo. Disponible en: https://bit.ly/2wWiwD0

Garcés, Cecilia (2003). Hablando del otro: categorías y estereotipos racistas en Guatemala. El caso de estudiantes de diversificado en cuatro centros educativos en la ciudad de Guatemala. Guatemala: Universidad de San Carlos.

González-Izás, Matilde (2012). "Transformación del Estado y territorio. Una invitación a continuar investigando". En Espacios Políticos, V(7): 31-60. Guatemala: Facultad de Ciencias Políticas y Sociales, Universidad Rafael Landívar.

González-Izás, Matilde (2015). Formación del Estado y disputas territoriales en el corazón del triángulo norte de Centroamérica. Siglos XIX y XX. Guatemala: Editorial de Ciencias Sociales.

Hun, Lourdes, Leslie Lemus e Iván Monzón (2006). "Respuestas de la sociedad civil al fenómeno de las maras y pandillas juveniles en Guatemala". En José Cruz (ed.), Maras y pandillas en Centroamérica: las respuestas de la sociedad civil organizada, vol. IV. San Salvador: UCA Editores, pp. 145-234.

Kurtenbach, Sabine (2012). Postwar Youth Violence: a Mirror of the Relationship Between Youth and Adult Society. Hamburgo: German Institute of Global and Area Studies. Working Papers, núm. 199.

Lemus, Carlos (2012). "Guatemala Bullying”. En Prensa Libre, sábado 10 de marzo. Disponible en: https://bit. ly/2wZgvGz.

Lemus, Leslie (2013). "Una mirada al contexto de generación de discursos sobre juventud en Guatemala hoy". En Jóvenes en Guatemala. Imágenes, discursos y contextos. Guatemala: AVANCSO, Instituto de Estudios Humanísticos-Universidad Rafael Landívar, pp. 149-256.

Levenson, Deborah (1988). Por símismos. Unestudiopreliminar sobre las "maras" en la ciudad de Guatemala. Guatemala: AVANCSO. Cuadernos de Investigación, vol. 4.

Levenson, Deborah (2013). Adiós niño. The Gangs of Guatemala City and the Politics of Death. Durham y Londres: Duke University Press.

López, M. y J. Samayoa (2009). Estigmatización juvenil, un fenómeno social en crecimiento. Estudio de la situación de jóvenes indígenas involucrados en maras o pandillas en el municipio de San Andrés Itzapa del departamento de Chimaltenango, Guatemala. Chimaltenango: CEADEL.

López, Stephanie (2012). Violencia sacrificial y discurso de poder sobre seguridad en la construcción del imaginario de los linchadores/vapuleadores: estudio de caso del vapuleo "El Reducto" enero 2010 y su correlación con los sujetos de seguridad generados en las propuestas de marketing político del 2007 (UNE, GANA, PP). Guatemala: Universidad Rafael Landívar.

Merino, Juan (2001). "Las maras en Guatemala". En Maras y pandillas en Centroamérica. Políticas juveniles y rehabilitación, vol. 1. Managua: UCA Publicaciones, pp. 109-217.

Merino, Juan (2004). "Políticas juveniles y rehabilitación de mareros en Guatemala". En Maras y pandillas en Centroamérica. Políticas juveniles y rehabilitación, vol. 3. Managua: UCA Publicaciones, pp. 89-119.

Merino, Juan (2007). "Guatemala. Variables de capital social asociadas a la presencia de maras". En Maras y pandillas en Centroamérica. Políticas juveniles y rehabilitación, vol. 2. Managua: UCA Publicaciones, pp. 115-158.

Morales, Henry (2007). ¿Por qué tanta frustración? La cooperación internacional en la década de la agenda de la pazen Guatemala. Guatemala: Editorial de Ciencias Sociales.

Ortiz, Gerson (2012). "Fallece niño víctima de 'Bullying' en Huehuetenango". En El Periódico, lunes 4 de marzo. Disponible en: http://www.elperiodico.com.gt/ es/20120304/pais/208971. 
Palma, Claudia (2012). . "Ley contra el 'Bullying' espera turno en el Congreso”. En El Periódico, domingo 29 de abril. Disponible en: https://bit.ly/2IrjVml.

Patzán, José y Glenda Sánchez (2016). "Cae banda de extorsionistas liderada por el Smiley". En Prensa Libre, lunes 4 de abril. Disponible en: http://bit. ly/2GLOymF.

PNUD (2007). Informe estadístico de la violencia en Guatemala. Guatemala: PNUD.

PNUD (2010). Guatemala: hacia un Estado para el Desarrollo Humano. Informe de Desarrollo Humano 2009/2010. Guatemala: PNUD.

PNUD (2012). Guatemala: iun país de oportunidades para la juventud? Informe Nacional de Desarrollo Humano 2011/2012. Guatemala: PNUD.

Rodríguez, Ernesto (2011). Políticas de juventud y desarrollo social en América Latina. Bases para la construcción de respuestas integradas. Documento de trabajo del VIII Foro de Ministros de Desarrollo Social de América Latina. San Salvador: UNESCO.
Samayoa, Claudia (2007). Las ejecuciones extrajudiciales de jóvenes estigmatizados. Dimensión jurídica, social y humana del fenómeno y la responsabilidad del Estado de Guatemala sobre la mal llamada "limpieza social". Guatemala: Front Line.

Sanford, Victoria (2008). Guatemala: del genocidio al feminicidio. Guatemala: F\&G Editores.

Savenije, Wim (2009). “iLa seguridad nacional en juego? Las transformaciones de las pandillas callejeras o 'maras' en Centroamérica'. En Santiago Bastos, Manuela Camus y Julián López (coords.), Guatemala: violencias desbordadas. Córdoba: Universidad de Córdoba, Servicio de Publicaciones, pp. 299-338.

Taracena Arriola, Arturo (2004). Etnicidad, estado y nación en Guatemala, 1944-1985, vol. II. Guatemala: CIRMA.

Tejeda, Rudy (2011). "El maltrato escolar no difiere en el campo". En Siglo XXI, jueves 3 de noviembre. Disponible en: http://www.s2l.com.gt/node/94890.

Waiselfisz, Julio Jacobo (2008). Mapa de violencia. Los jóvenes en América Latina. Brasil: Red de Información Tecnológica Latinoamericana. 
Imagen 1. Crónica de la transformación de la mara Salvatrucha en los barrios de Ciudad Guatemala

Las comunidades del Puente Belice se encuentran localizadas al norte de Ciudad Guatemala, una de las áreas con mayores niveles de violencia en la actualidad, pero también con problemas de exclusión social que le anteceden -escasez de vivienda y servicios, pobreza, informalidad laboral, riesgos medioambientales, entre otros-. La evolución que experimentó la mara Salvatrucha en este territorio sirve para ilustrar el argumento de que la violencia juvenil es un fenómeno que necesita ser comprendido en perspectiva histórica.

Etapa 1 (1996-1997): “... hueviábamos* gallinas y hacíamos fogatas para cocinarlos..."

Etapa 2 (1998-2000): "... los 18's quedaron en medio..."

Etapa 3 (2000-2003): “... la Familia no se toca...”

Etapa 4 (2003-2007): “... me dijo que me iba a descuartizar... yo había empezado a juntarme con los de la iglesia..."

Etapa 5 (2007-2013): "... empezó a cambiar cuando vinieron las clicas de fuera..."

*Robar

Fuente: elaboración propia basada en AESU, 2014. 